\begin{tabular}{l|ll} 
J B E & $\mid \begin{array}{ll}\text { JOURNAL OF } \\
\text { BIOLOGY }\end{array}$ & $\begin{array}{l}\text { E-ISSN 2656-3436/ P-ISSN 2615-3947 } \\
\text { IAIN KUDUS } \\
\text { Tersedia online: http://journal.iainkudus.ac.id/index.php/jbe }\end{array}$ \\
\hline
\end{tabular}

\title{
Pembelajaran Picture and Picture untuk Meningkatkan motivasi dan Hasil Belajar Siswa Pada Materi Invertebrata
}

\author{
Mansur S ${ }^{1}$, Sulasfiana Alfi Raida ${ }^{2}$, Sukarman Hadi Jaya Putra ${ }^{3}$ \\ Universitas Nusa Nipa, Indonesia, 86111 1,3 \\ Institut Agama Islam Negeri Kudus ${ }^{2}$ \\ mansursaputra00@gmail.com
}

\begin{abstract}
ABSTRAK
Penelitian ini bertujuan untuk meningkatkan motivasi dan hasil belajar siswa kelas X SMAS Katolik Caritas Maumere dengan menerapkan model pembelajaran picture and picture pada materi Invertebrata. Penelitian ini merupakan penelitian deskriptif dengan metode penelitian tindakan kelas (PTK). Penelitian dilaksanakan pada bulan Mei 2018 dengan subyek penelitian adalah 20 siswa kelas X SMAS Katolik Caritas Maumere tahun ajaran 2017/2018. Penelitian ini terdiri dari 2 siklus, setiap siklus terdiri dari 3 kali pertemuan. Hasil belajar ranah kognitif dan ranah afektif diperoleh dari hasil post-test juga lembar observasi. Hasil motivasi belajar diperoleh dari hasil lembar kuisioner pada siklus I dan siklus II. Hasil penelitian menunjukkan bahwa penerapan model pembelajaran metode picture and picture pada pokok bahasan Invertebrata dapat meningkatkan hasil belajar ranah kognitif dari rata rata skor siklus I 78,5 menjadi 86,75 di siklus II dan persentase pencapaian KKM dari $70 \%$ di siklus I menjadi $100 \%$ di siklus II dan peningkatan motivasi belajar dari 69,68\% kriteria minimal sedang di siklus I menjadi $86,87 \%$ di siklus II pada kriteria tinggi. Kesimpulan yang diperoleh dari penelitian ini adalah penerapan model pembelajaran picture and picture dapat meningkatkan motivasi dan hasil belajar siswa pada materi pokok Invertebrata kelas X SMAS Katolik Caritas Maumere.
\end{abstract}

Kata kunci : Picture and Picture, Hasil Belajar, Motivasi 


\begin{abstract}
This study aims to improve the motivation and learning outcomes of students of class X SMAS Katolik Caritas Maumere by applying the model of learning picture and picture on Invertebrate materials. This research is a descriptive research with class action research method (PTK). The research was conducted in May 2018 with the subject of research is 20 students of class X SMAS Katolik Caritas Maumere academic year 2017/2018. This study consists of 2 cycles, each cycle consists of 3 meetings. The learning outcomes of the cognitive and affective domains were derived from post-test results as well as observation sheets. The result of learning motivation is obtained from the result of questionnaire in cycle I and cycle II. The results showed that the application of learning model picture and picture method on the subject of Invertebrata can improve the learning outcomes of cognitive domain from the average score of cycle I 78.5 to 86.75 in cycle II and the percentage of KKM achievement from $70 \%$ in cycle I to $100 \%$ in cycle II and improvement of learning motivation from 69,68\% minimum criterion is in cycle I become $86,87 \%$ in cycle II on high criterion. The conclusion obtained from this research is the application of picture and picture learning model can increase motivation and student learning outcomes on the subject matter of Invertebrate class X SMAS Katolik Caritas Maumere.
\end{abstract}

Keyword: picture and picture, learning result, motivation,

\title{
PENDAHULUAN
}

Salah satu komponen yang disorot dalam dunia pendidikan sebagai bagian dari proses pencerdasan kehidupan bangsa adalah guru. Guru memberikan proses pembelajaran yang diperlukan adanya motivasi pada diri siswa untuk mendorong mereka melakukan aktivitas di dalam kegiatan pembelajaran. Pelaksanaan pembelajaran adalah interaksi guru dan siswa dalam rangka menyampaikan bahan pelajaran untuk mencapai tujuan pembelajaran yang diharapkan akan mendapatkan hasil pembelajaran yang memuaskan.

Pembelajaran adalah kegiatan guru secara terprogram dalam desain instruksional untuk membuat siswa belajar secara aktif, yang menekankan pada penyediaan sumber belajar. Pembelajaran tidak terjadi seketika, tetapi sudah melalui tahapan perancangan pembelajaran (Dimyati dan Mudjiono, 2015). Proses pembelajaran perlu direncanakan, dilaksanakan, dinilai, dan diawasi agar terlaksana secara efektif dan efisien. Pembelajaran sebagai proses belajar yang dibangun oleh guru untuk mengembangkan kreativitas berpikir yang dapat meningkatkan kemampuan berpikir siswa, serta dapat meningkatkan kemampuan mengkonstruksi pengetahuan baru sebagai upaya meningkatkan penguasaan yang baik terhadap materi pelajaran biologi. Biologi merupakan ilmu yang mempelajari mahkluk hidup. Untuk mencapai tujuan seperti yang diharapkan tentu saja dibutuhkan adanya kerjasama yang baik antara guru dan siswa. Siswa harus memiliki keaktifan tinggi dalam proses belajar mengajar, sedangkan guru harus mampu mengadakan pembelajaran yang melibatkan siswa. 
Hasil observasi yang dilakukan di SMAS Katolik Caritas Maumere menunjukkan bahwa motivasi dan hasil belajar siswa belum mencapai Kriteria Ketuntasan Minimum (KKM) yang ditetapkan sekolah yaitu 75. Hal ini dapat dilihat dari 20 siswa yang mengikuti Kegiatan Belajar Mengajar (KBM) dan yang mencapai KKM hanya 9 orang dengan persentase ketuntasan klasikalnya adalah 54,55\% sedangkan 11 orang lainnya tidak tuntas dengan persentasenya adalah $45,45 \%$. Hal ini disebabkan karena siswa malas untuk belajar dan tidak terlibat aktif dalam pembelajaran. Motivasi yang diberikan kepada siswa harus disertakan dengan metode dan model pembelajaran yang bervariasi.

Motivasi adalah dorongan mental yang menggerakkan dan mengarahkan perilaku manusia, termasuk perilaku belajar. Hasil belajar merupakan hasil dari suatu interaksi tindakan belajar mengajar. Dari sisi guru, tindakan mengajar diakhiri dengan proses evaluasi hasil belajar. Dari sisi siswa, hasil belajar merupakan berakhirnya penggal dan puncak proses belajar (Dimyati dan Mudjiono, 2015).

Guru diharapakan dapat meningkatkan motivasi dan menemukan variasi belajar dalam menggunakan metode dan model pembelajaran yang baik agar siswa dapat memahami materi yang disampaikan. Pemilihan metode dan sumber belajar yang baik akan mempermudah proses balajar biologi. Model pembelajaran yang tepat dan sesuai akan sangat membantu tercapainya tujuan pembelajaran. Penggunaan model pengajaran yang kurang menarik dapat menimbulkan suatu masalah, yaitu rendahnya motivasi dan hasil belajar siswa. Guru sebagai pengajar perlu mengatasi hal tersebut, dengan menerapkan metode atau model pembelajaran yang lebih menarik bagi siswa dan tidak membosankan agar dapat membangkitkan motivasi dan hasil belajar siswa dalam pembelajaran.

Model picture and picture merupakan model pembelajaran yang kooperatif atau mengutamakan adanya kelompok-kelompok dengan menggunakan media gambar yang dipasangkan atau diurutkan menjadi urutan logis (Kurniasih dan Sani, 2015). Model pembelajaran picture and picture merupakan model pembelajaran yang menggunakan media gambar yang dipasangkan atau diurutkan secara logis, Suprijon (2010) dalam Huda (2013). Penggunaan media gambar dan pembelajaran yang dilakukan secra kooperatif dapat menumbuhkan motivasi siswa dala belajar. Riyono dan Retnoningsih (2015) model pembelajaran picture and picture dengan strategi inkuiri efektif terhadap motivasi dan hasil belajar siswa (afektif, psikomotorik dan kognitif) pada materi protista

Fauzi dkk. (2011), dalam penelitiannya menyatakan bahwa, penerapan pembelajaran kooperatif picture and picture dapat meningkatkan motivasi belajar biologi siswa kelas VIII D SMP N 14 Surakarta tahun pelajaran 2011/2012. Sejalan dengan penelitian Sasmita dkk (2015) penerapan model pembelajaran kooperatif tipe picture and picture dapat meningkatkan hasil belajar mata pelajaran prakarya dan kewirausahaan (rekayasa) pada siswa kelas XI MIPA 1 SMA Negeri 3 Singaraja, Sejalan dengan penelitian dari Nasution, dkk. (2014), penggunaan model pembelajaran picture and picture pada materi sistem 
pencernaan makanan pada manusia dapat memberikan pengaruh yang positif dan signifikan terhadap hasil belajar dan motivasi belajar peserta didik.

\section{METODE PENELITIAN}

\section{Jenis Penelitian}

Penelitian tindakan kelas ini digunakan untuk memecahkan masalah yang dihadapi dan dialami secara langsung oleh peleliti dalam melakukan pembelajaran invertebrata dengan menggunakan model pembelajaran picture and picture dengan menggunakan model yang dikemukakan oleh Khemmis dan Mc Taggart tahun 2012. Secara umum desain PTK yang dilakukan seperti pada Gambar 1.

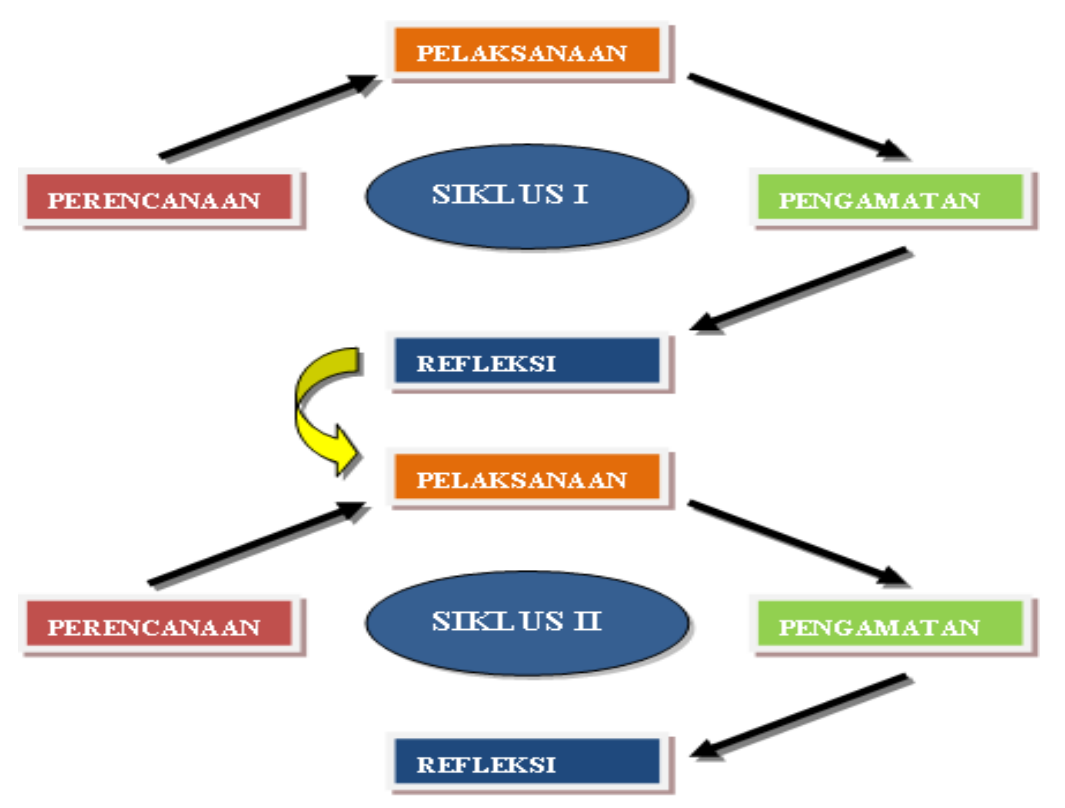

Gambar 1. Desain PTK model Khemmis dan Mc Taggart (Tanniredja, 2012)

\section{Waktu dan Tempat Penelitian}

Penelitian akan dilakukan di SMAS Katolik Caritas Maumere, dari tanggal 24 s/d 31 Mei 2018 Tahun Ajaran 2017/2018.

\section{Prosedur Penelitian}

Penelitian ini dilaksanakan dalam dua siklus. Siklus I dan siklus II masing-masing terdiri dari tiga kali pertemuan dengan rincian dua kali pertemuan kegiatan belajar mengajar dan satu kali tes pada akhir siklus. Kegiatan belajar dalam satu minggu dilakukan sebanyak tiga kali pertemuan. Tiap siklus akan dilaksanakan secara bertahap sesuai dengan perubahan dan target yang ingin dicapai. Penelitian ini terdiri dari dua siklus masing-masing siklus terdiri dari empat tahapan yaitu perencanaan, pelaksanaan, observasi dan refleksi. 


\section{Analisis Data}

Hasil belajar siswa pada aspek efektif diukur melalui lembar observasi yang diamati oleh observer yang berjumlah dua orang, dari hasil observasi kedua orang tersebut dicari ratarata sehingga peneliti dapat mengetahui bagaimana sikap siswa di kelas ketika mengikuti kegiatan pembelajaran. Rata-rata persentasi ranah efektif siswa diperoleh dari pertemuan pembelajaran setiap siklus, ranah efektif setiap siswa dianalisis dengan menggunakan deskriptif kuantitatif yaitu, dengan mencari persentasi tertinggi pada setiap kategori kemudian diambil rata-rata keseluruhan kategori siswa seluruh siswa berdasarkan pengamatan dari observer. Rumus yang digunakan adalah sebagai berikut:

$$
p=\frac{q}{r} \times 100 \%
$$

keterangan:

$\mathrm{p}=$ persentasi skor hasil observasi kelompok siswa

$\mathrm{q}=$ jumlah keseluruhan skor yang diperoleh kelompok

$\mathrm{r}=$ skor maksimal (total skor)

\section{HASIL DAN PEMBAHASAN}

Berdasarkan hasil analisis pada siklus I dan II terdapat hasil penelitian seperti pada gambar 2 dan 3.

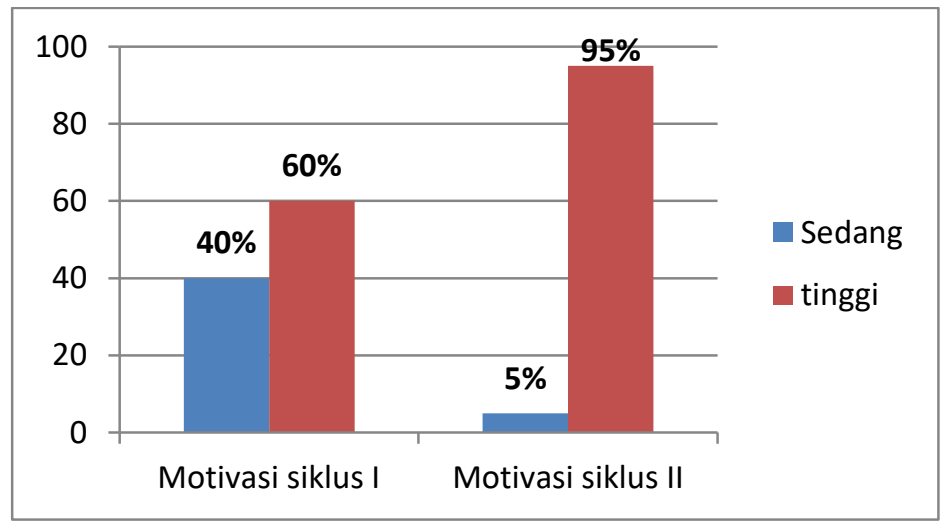

Gambar 2. Perbandingan Persentase Motivasi pada siklus I dan siklus II 


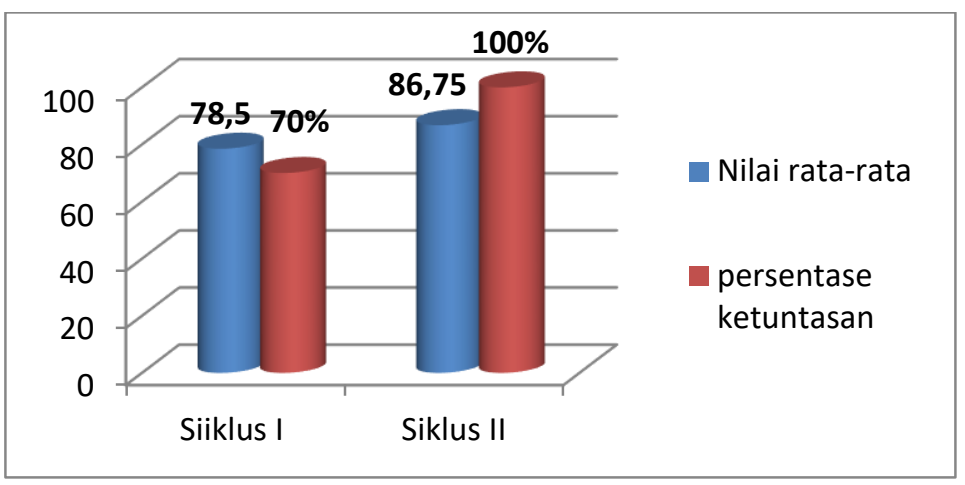

Gambar 3. Perbandingan Nilai Kognitif pada Siklus I dan Siklus II

Motivasi dalam belajar sangat diperlukan untuk meningkatkan hasil belajar siswa. Siswa yang memilki motivasi tinggi dalam belajar akan bersemangat, aktif dalam menggali pengetahuan dan hal yang belum diketahui oleh siswa dalam kegiatan pembelajaran. Apabila motivasi belajar siswa rendah, siswa akan cenderung menjadi malas sehingga hasil belajar menurun.

Dari data yang peneliti peroleh dalam perhitungan hasil kuesioner menunjukkan bahwa motivasi siswa siklus I pada mata pelajaran biologi yaitu $60 \%$ tinggi dan $40 \%$ sedang. Pembelajaran model picture and picture ini memiliki banyak kelebihan sehingga membuat siswa termotivasi dengan pembelajaran yang telah berlangsung, diantaranya yaitu suasana pembelajaran menjadi lebih menyenangkan karena siswa dapat melihat secara langsung gambar yang berkaitan dengan materi dan siswa juga mendapat kesempatan untuk mengembangkan kemampuan berpikir yang logis. Sejalan dengan penelitian Fauzi dkk (2011) penerapan pembelajaran kooperatif Picture and Picture dapat meningkatkan motivasi belajar biologi peserta didik. Hasil observasi motivasi belajar biologi peserta didik pada siklus I mencapai 74,06 \% dan pada siklus II rata-rata mencapai 86,87\%.

Pada siklus I penelitian ini memperoleh nilai rata-ratanya yaitu 78,5. Jumlah siswa yang mencapai KKM dari $70 \%$ pada siklus I ini terdapat enam siswa yang tidak tuntas. Siklus I hasil post-test siswa dapat dikatakan belum mencapai indikator yang ditetapkan oleh peneliti, indikator yang diinginkan peneliti yaitu $75 \%$ dan pada siklus I belum mencapai ratarata kelas $70 \%$. Namun masih ada siswa yang belum mencapai KKM, oleh karena itu peneliti ingin ketuntasan siswa mencapai $100 \%$ atau tidak ada siswa yang memperoleh nilai tidak tuntas.

Puspita dkk (2012), hasil belajar biologi siswa yang menggunakan strategi pembelajaran aktif model picture and picture pada kelas eksperimen lebih tinggi yang menunjukkan nilai 72,40 dibandingkan pada pembelajaran konvensional dengan nilai 67,57. Hasil belajar pada aspek afektif dengan menggunakan strategi pembelajaran aktif model picture and picture menunjukkan nilai yang lebih tinggi yaitu dengan rata-rata 87,97 \% pada 
kelas eksperimen dibandingkan dengan kelas kontrol yang menggunakan pembelajaran konvensional yaitu dengan rata-rata $85,13 \%$, sedangkan hasil belajar pada aspek psikomotor dengan menggunakan strategi pembelajaran aktif model picture and picture menunjukkan nilai yang lebih tinggi yaitu dengan rata-rata $87,37 \%$ pada kelas eksperimen dibandingkan dengan kelas kontrol yang menggunakan pembelajaran konvensional yaitu dengan rata-rata $64,73 \%$.

Pada penelitian siklus I hasil nilai rata-rata post-test siswa yaitu 78,5 dan ketuntasan belajar siswa yang mencapai KKM yaitu 100\%. Pada penelitian ini pada siklus I dapat dikatakan berhasil karena hasil post-test pada siklus I telah mencapai target yang diinginkan. Peneliti melihat peningkatan hasil belajar kognitif siswa juga dipengaruhi oleh suasana pembelajaran yang lebih baik dibandingkan dengan siklus I. Peneliti memperbaiki proses pembelajaran yang terjadi di siklus I, yaitu dengan cara membagi kelompok secara rata berdasarkan hasil kognitif siswa pada siklus I. Sehingga dalam siklus I, kelompok belajar siswa menjadi rata antara siswa yang memiliki hasil belajar tinggi dengan siswa yang memiliki hasil belajar yang sangat rendah atau belum mencapai KKM. Dengan demikian dalam kelompok belajar di siklus I semua siswa dalam kelompok akan terlibat aktif dan siswa yang tidak tahu akan menjadi tahu ketika mereka membagi pengetahuan antara sesama teman yang belum memahami.

Hasil observasi pada siklus I terdapat 4 kelompok yang di observasi oleh observer memperoleh nilai dengan rata-rata di bawah $75 \%$. Dapat di kategorikan sedang dengan persentase 69,68\%. Natalina dkk (2009), menyatakan bahwa rata-rata observasi belajar siswa dalam proses pembelajaran meningkat dari 78,41\% (baik) pada siklus I menjadi 82, $28 \%$ (baik) pada siklus II dalam pembelajaran dengan menggunakan model pembelajaran kooperatif picture and picture.

\section{SIMPULAN}

Penerapan model pembelajaran picture and picture dapat meningkatkan motivasi siswa pada materi invertebrata di SMAS Katolik Caritas Maumere, persentase pada siklus I yaitu $60 \%$ dengan kategori sedang dan pada siklus II mencapai target yaitu $95 \%$ dengan kategori tinggi. Penerapan model pembelajaran picture and picture dapat meningkatkan hasil belajar siswa pada materi invertebrata di SMAS Katolik Caritas Maumere mengalami peningkatan menjadi $8,25 \%$. Sedangkan untuk persentase jumlah siswa yang mencapai KKM pada siklus I yaitu 70\% meningkat pada siklus II menjadi 100\%. 


\section{DAFTAR PUSTAKA}

Dimyati dan Mudjiyono. 2015. Belajar dan Pembelajaran. Jakarta: Penerbit Rineka Cipta

Fauzi, R., Dwiastuti. S, dan Harlita 2011. Penerapan Metode Pembelajaran Picture and Picture Untuk Meningkatkan Motivasi belajar Biologi siswa Kelas VIII D SMP Negeri 14 Surakarta. Jurnal Pendidikan Biologi. No. 3, Vol 3.

Huda, M. 2013. Model-Model Pengajaran dan Pembelajaran Isu-Isu Metodis dan Paradigmatis. Yogyakarta Pustaka Pelajar.

Kurniasih, I., dan Sani. B, 2015. Ragam Pengembangan Model Pembelajaran untuk Peningkatan Profesionalitas Guru. Jakarta Kata Pena.

Nasution, S. H., Lestari, R dan Dahlia. 2014. Pengaruh Model Pembelajaran Colek Pipi (Cooperative Learning Ko Picture and Picture) terhadap Motivasi dan Hasil Belajar IPA Peserta Didik Kelas VII SMP Muhammadiyah Rambah Kabupaten Rokan Hulu. Jurnal Pendidikan Biologi.

Natalia, M., Yusuf, Y. dan Rahmayani. D 2009. Penerapan Model Pembelajaran Kooperatif Picture and Picture untuk Meningkatkan Aktivitas dan Hasil Belajar Biologi Siswa Kelas XII IPA SMAN I Ukui. Jurnal Pendidikan Biologi Jurusan Pendidikan MIPA FKIP Universitas Riau.

Puspita, M., Gusmaweti dan Azrita. 2012. Penerapan Strategi Pembelajaran Aktif Model Picture and Picture Dalam Pembelajaran Biologi Siswa kelas VII SMPN 1 Tiumang Kabupaten Dharmasraya. Dharmasraya: Jurnal Pendidikan Biologi.

Riyona, B dan Retnoningsih, A. 2015. EFEKTIVITAS MODEL PEMBELAJARAN PICTURE AND PICTURE DENGAN STRATEGI INKUIRI TERHADAP MOTIVASI DAN HASIL BELAJAR SISWA. Unnes Journal of Biology Education. Unnes. https://journal.unnes.ac.id/sju/index.php/ujbe/article/view/8907/5827

Sasmita, G. A. D., Gitakarma, M. S dan antiyadnya. 2015. Penerapan Model Pembelajaran Kooperatif Tipe Picture and Picture untuk Meningkatkan Hasil Belajar Prakarya dan Kewirausahan Siswa di Kelas XI Mipa 1 SMAN 3 Singaraja. E-jurnal JPTE Universitas Pendidikan Ganesha. Vol. 4, No. 1.

Taniredja, T., Pujiati, I,. Dan Nyata, 2012. Penelitian Tindakan Kelas untuk Pengembangan Profesi Guru. Bandung Alfabeta 